\title{
Experience with Nursing Students using Interactive Video Conferencing Lischen Haoses-Gorases
}

Faculty of Health Sciences, School of Nursing, University of Namibia 2002@iway.na

\begin{abstract}
Interactive video conferencing is a means of communication that has revolutionised opportunities for reaching students over a vast distance as opposed to past practices when students or lecturers had to travel long distances for contact sessions. It is imperative in current challenging educational systems that each lecturer be acquainted with the modern technology in transmitting of knowledge and skills. The purpose of this article is to share my personal experience with Interactive videoconferencing with Nursing students. This method was challenging to me in the beginning, but as lecturers progressed it went well and students enjoyed the lectures according the statements made by themselves. This method, despite many challenges this teaching method has far reaching and long lasting effects with good and effective planning that will result in success.
\end{abstract}

\section{Indexing terms/Keywords}

Experiences; interactive; video conferencing; nursing; students

\section{Academic Discipline And Sub-Disciplines}

Nursing Education

\section{SUBJECT CLASSIFICATION}

Human Anatomy and Applied Biophysics

\section{TYPE (METHOD/APPROACH)}

Distance Mode (Video conferencing)

\section{INTRODUCTION}

There is no doubt that interactive video conferencing has its place in higher education institutions the world over, and Namibia is no exception. However, individual lecturers, instructors or students have different perceptions and experiences with the video conferencing format in general.

Distance teaching is different form a classroom teaching experience. It is imperative that distance educators are willing, able and ready to deliver and transmit knowledge and skills across the distance. These educators are sometimes off-the cuff required to author, organise content into curricula, deliver it on demand across any device and track the results. When students on the other hand, learn in a dynamic digital setting, they will have an affinity for video collaboration, whether they listen to a lecture, group study, or present a project. Interactive video conferencing This involves an LCD Screen, a microphone and a camera working together. If you use a telephone line or a network or the internet provider's connection, you "dial up "another location with the same set up. You can in "real-time" see and hear the other person (student or lecturer), and vice-versa. Students are able to talk to you or respond to you and sometimes they can even interact with each other. They can also access resources that would otherwise be unavailable due to distance and time. Video conferencing is a very effective method and it needs a second look. 


\section{INTERACTIVE VIDEO CONFERENCING WITH NURSES}

Interactive video conferencing as a means of communication that has revolutionised opportunities for reaching students over vast distance, as opposed to past practices when students or educators had to travel extensively for contract sessions.

In my experience, video conferencing is multi-dimensional; it has multiple benefits, but also challenges. As the University of Namibia has recently extendend its services to all regions in the country, it is of essence that all students are equally well taught. I had to lectures Human Anatomy and Applied Biological Sciences for the first Semester to $1^{\text {st }}$ year students in Keetmanshoop, UNAM's Southern Campus.

Due to the fact that I am designated to work at the main campus in Windhoek, I could not travel to the South as I had to attend to my students at the main campus as well I therefore had no choice but to interact with students via video conferencing to accommodate the UNAM Southern campus students.

The challenge I had was that this course was never taught in distance mode. Despite the challenge, the situation created an opportunity to turn to the highly competent Centre for eLearning and interactive Multimedia (CeLIM) staff for assistance.

I was immensely organised to tackle what looked like a mammoth task at the time. It is important though, that thorough planning is done, because lecturers or instructors should stay focused and connected with their students. A backup plan is therefore necessitated through uploading notes on the student's portal beforehand in the event of a technical failure (Pennsylvania State University 2006).

I taught Human Anatomy and Applied Biological Sciences for couple of years, but my fear surfaced when I started to ask myself the following questions;

1. How will I meet the needs of all the students?

2. Will I be able to interact with my students effectively?

3. As my subject is a practical life Human Anatomy course, how do I deliver it in a meaningful manner?

4. Will this method not frustrate me in my reaching out to students, or being able to walk amongst them or physically touch them?

5. How can I be sure whether students will follow my lectures to the maximum? The facial expressions of students in such a large group is hard to observed.

6. How will I maintain discipline and order in the virtual classroom like this?

7. How can I demonstrate a human anatomy model to the students effectively

8. How will I strengthen or follow up and enhance theory with practical demonstrations?

After all, there was nothing I could do to change the situation. My confidence and experience on the subject matter did however serve as tools to success.

I transformed challenges into opportunities for the sake of my students, who expected the same quality as my other students, via distance mode. 


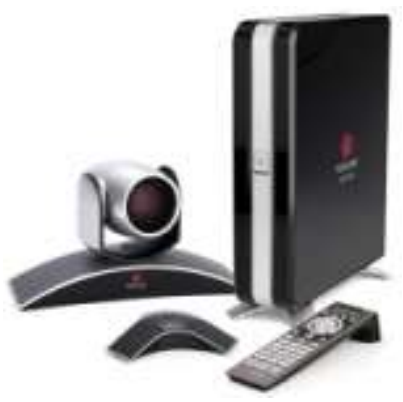

Fig. 1 Polycom HDX Series

\section{VIDEO CONFERENCING BENEFITS}

Video conferencing has made its way into the classroom and has been proved to have innumerable benefits. Firstly, technology has advanced in remote areas and is limitless in terms of knowledge-base, communication, distance and time factors. Educators can expand their skills and knowledge through networking and by making use of the global network knowledge base.

Secondly, I realised that video conferencing is more lively and not as boring, compared to classroom presentations. Thirdly, to participate actively via video conferencing students used a certain level of pre-knowledge, like handouts or a prescribed textbook to gain the most from the experience. Students communicated their thoughts freely, confidently, clearly and were mostly lively by way of interaction. The requirement here is two way sharing and not necessarily one way communication. It cuts on travel costs and improves access to learning as insinuated by Martin (2005) and Townes and Erving 2005. The question that can be asked is whether this adequately serves the needs of the various students? Another question that came to mind was if students were given a choice to select video conferencing over face to face teaching methods, which method would they choose? Video conferencing seems to be an effective method if the lecturer uses appropriate media with the video conferencing to enhance learning. According to a study by Dogget (2008) on video conferencing, students had different views on this mode of interaction $-80 \%$ of the students who were involved in the study agreed that they would have been more comfortable in a virtual class setting and $57 \%$ agreed that video conferencing was a barrier to their interaction with the instructors, whereas $32 \%$ agreed that they would not have taken the class if they had known that it was going to be delivered via video conferencing.

The students taught via video conferencing as well as the lecturer, who joined the class in the southern campus were of the opinion that the lectures were clear. They expressed appreciation for the visit I paid to them to give human anatomy practical sessions. Their tests, assignments and semester course after completion, as this only takes place in May 2015 . The new appointee will be appointed in the second semester 2015 to teach the above course face to face, as this method most favoured by the majority of students.

\section{Benefits/Opportunities/Value Drivers}

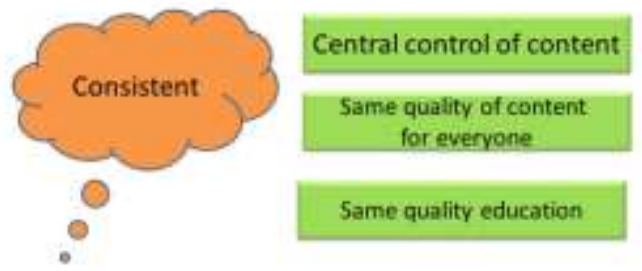

Fig 2: Benefits/Opportunities/Values Drivers 


\section{LIFE EXPERIENCE: INTERACTIVE VIDEO CONFERENCING EQUIPMENT}

The following are some of the quotations of students who experienced the teaching via interactive video conferencing.

These students were stationed $500 \mathrm{~km}$ from the main campus and the first group who enrolled for BSc. Nursing Degree at the Southern Campus.

One student "said "The classes for Human Anatomy last year was so enjoyable I enjoyed her teaching. We learned a lot and understand the content at the distance.

It is important to transfer knowledge in a way that students understand, internalized and provide correct feedback.

Another stated" Video was conferencing was so important to me, because, interestingly, remembered most of the content, osteology in particular, despite the fact that it was lot of theory! The fact that students enjoyed the modern mode of teaching was most encouraging and motivates you to go for an extra mile to deliver beyond expectations. Other said" Video conferencing was good and important to us, because without this foundation we could not manage the second year so far, I am very thankful for all the efforts."

Another states "The Anatomy video conferencing was great and up to the standard, as well as awesome. It was most educative and taught us new way of learning, because there was a good interaction with the lecturer". Another student said "The video conferencing was not a good idea in the beginning, because the system was new to us, but as time goes, we used to enjoy it. Presentations were clear and we could ask questions immediately. The teacher made sure that we followed the lecturer; we have a great time with her.

Some said "We students from Southern Campus scored above $70 \%$ and have $100 \%$ pass rate and remember, we have always trust in you Doctor." This seems to proof that students enjoyed the video conferencing of the subject. "Human Anatomy and found it interesting. It is imperative to create a dictactic, conducive and learner friendly environment in which learner can interact with the lecturer, especially students live in geographically distant locations.

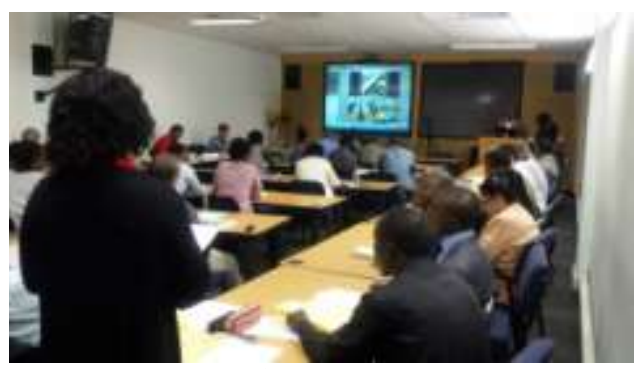

Fig. 3: Video Conferencing meeting

Quality in higher Education is the extent to which the education provided by an institution consistently meets the standards defined by that institution in relate its goal and mission Quin and Hughes; (2007).

Another student said Anatomy is not an easy subject, but you have made us to understand it over the distance now, we know the course from Ananium to phalanges "You found may be difficult to teach us and some you could not see us, due to technological challenges, but it happen we all have passed the course"

Furthermore another student stated "Distance does not play a vital role, as the way you explained the content made it that it was just a building and nothing could hinder us to understand the Anatomy content. You came down $550 \mathrm{~km}$ to the South for physical practical sessions with us, this was exciting to us and especially osteology study of bone... 
If theory is followed up and enhanced with the practical sessions applicable to the specific body system, then learning is anchored. I could see the eagerness and courage in each student when we were engaging in Anatomy Practical sessions, although my teaching slides also reflected diagrams/figures.

A student said "Lectures through Video conferencing with this Anatomy Lecturer was very educative and lectures were very clear for us to understand. Despite the distance or no face to face classroom teaching it was possible to follow the topics through this technology".

Despite all the fears of not be sure that I will attain my objectives through the video conferencing method used for teaching as the first time experience and positive comments from some of the students was clearly demonstrated that is possible to teach this practical subject through the video conferencing. At the end of semester examination all the students passed the subject and majority obtained above $70 \%$ in their first semester June examination which enable them to proceed to semester two course.

\section{Challenges:}

- To have an instructor in a classroom is always favourable or desirable in regards to student learning opposed to video conferencing

- Another challenge was that because I could not view all the students' faces and their non verbal facial expressions, there were no clear cues to see whether they understood the content or not. Although they answered my questions.

- I agreed with Canning (1999) that ambiguities can be effectively resolved in face to face conversations by providing immediate feedback.

- The majority of students can be easily intimidated by the technology and prevent not to pose challenging questions or seek for more clarifications.

- This method will never replace face to face education where the life long bonds will be created unlike via technology, because every effort is made to touch their mind which is great obstacle with Video conferencing.

\section{Solutions to some challenges}

- It will be advisable not to teach practical subjects such as Human Anatomy via Video conferencing or select not hard to teach subjects via this modified method of instruction

- Interactive video conferencing should be for smaller intimate groups of students, not big groups of more than 50 .

- Design rooms in order for the lecturer to see all the students and keep the camera away from the students walking isles. Some students might hide behind the camera.

- Training of lecturers is very important to operate these instruments, but also to include how to prepare quality learning material, ways to improve presentations skills, voice techniques and how to promote interaction between the lecturer and students.

- Students cannot be controlled in large groups or left unsupervised since they will talk to each other, walk around etc and be disruptive. There needs to be discipline and control but I may not be easy.

- Although there will be negative cost implications, there should be a class coordinator at the remote site during each class activing as the assistant lecturer in order for students to make valuable contributions.

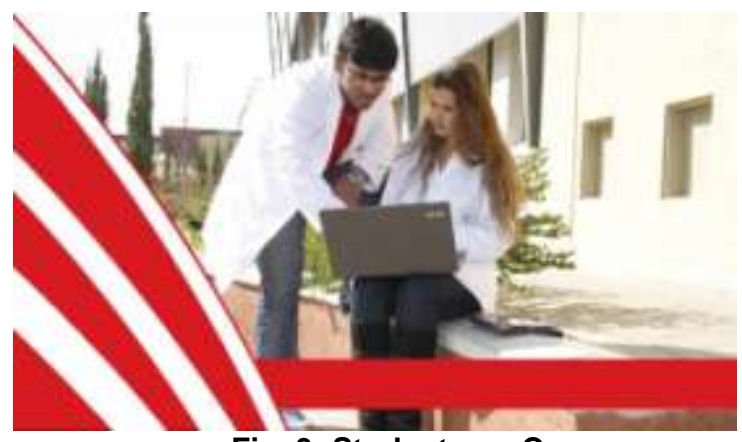

Fig. 3: Students on Campus 


\section{CONCLUSION}

Video conferencing format have both challenges to students and staff. Therefore it is imperative that this method be used carefully and with thorough planning. It also placed additional demands on the instructors because they used to change their modus operandi, manage equipment, to be sensitive to the camera and the student on the teaching sites. These challenges and solutions are my own observations like many others have discovered in their students surveys. Finally, it is believed that besides so many challenges, this method/technology has for reaching and long lasting effects, with good physical resources, material content, professional experienced educators with good instruction on how to instruct hard to teach subjects, effective communication with high standards and quality focussed. It can really work! 


\section{REFERENCES}

1. Canning, $\mathrm{R}$ (1999). The use of video conferencing for personal and continuing development in H.E. a small group study journal of further and Higher Education 23, 1, 117-130.

2. Dogget, M (2008). The video conferencing in classrooms. "What do the students think vol. 44. No. 4. Western Kentucky University.

3. Freeman, M (1998). Video conferencing a solution to the Multi-campus large classes problem? British journal of Educational Technology. 29, 3, 197-210.

4. Martin, M (2005). Seeing is believing. The role of video conferencing in distance leaving British journal of educational Technology 36 (3), 397-405.

5. Minnot, A.M, Islands M.C. (2010). I.A Video conferencing technology Benefits and Challenges arising from its use in a Caribbean Island State University.

6. Pennsylvania State University Technologies. College of Agricultural Sciences (2006).

7. Townes Young, K, L and Ewing, V. R. (2005). Creating a global classroom T. H. E. journal 33 (4): 43-5.

\section{Author' biography with Photo}

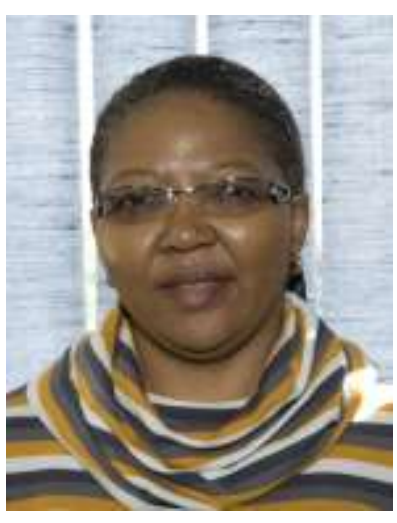

An Associate Professor, Lischen Haoses-Gorases was a Dean of Faculty of Medical and Health Sciences for the 8 years within the University of Namibia. (Unam) I am Namibian. I live in Windhoek, capital city of Namibia. I am employed by the University of Namibia and in service for 30 years. Furthermore, I commenced with my General Nursing training in Windhoek in 1975, after which I obtained the General Diploma in Nursing in 1977. Thereafter I pursued my Midwifery at the Peninsula Maternity Hospital in Cape Town .In 1981 I continued with my studies in Advanced University Diploma in Community Health and Nursing Education at University of Western Cape (UWC), BA Cur at UNISA, Honors' Degree at Academy, Windhoek, Masters Degree at the same institution and the Doctorate in Nursing Science at the University of Namibia. I was the President of Nurses Association for 8 years President, the founder member and President of Namibian Planned Parenthood Association, a Non-governmental organization for another 8 years. Currently, I am the Vice Chairperson of the Regional Coordinating Mechanism on TB in the Mining Sector and also the Vice Chairperson of the National Council of Higher Education. Furthermore, I also serve on the Namibia National Commission of UNESCO and member of the National Coordinating Committee on HIV/Aids, Tuberculosis and Malaria. I am still an Associate Professor and lecturer in the Faculty of Health Sciences. University of Namibia.

My interest areas are; HIV and AIDS, Gender Education and Research (specifically in HIV and AIDS, TB and Malaria). At regional level, I also served on the following committees, namely; CODATA Of ICSU, RSA, Sub-Committee on Human and wellbeing from ICSU.

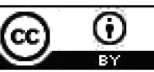

This work is licensed under a Creative Commons Attribution 4.0 International License.

DOI :10.24297/ijrem.v7i5.4330 